\title{
Interpersonal Values and Academic Performance Related to Delinquent Behaviors
}

\author{
María Del Mar Molero Jurado, María Del Carmen Pérez Fuentes*, \\ Antonio Luque De La Rosa, África Martos Martínez, Ana Belén Barragán Martín and \\ María del Mar Simón Márquez
}

Department of Psychology, University of Almería, Almeria, Spain

The present study analyzes the relation between delinquent behaviors, interpersonal values, and academic performance. It also analyzes the possible protective function of interpersonal values against delinquent behaviors. The Interpersonal Values Questionnaire (IVQ) was used to assess interpersonal values, and the Antisocial-Delinquent Behaviors Questionnaire (A-D) was employed to assess antisocial behaviors. The sample was made up of 885 students of Compulsory Secondary Education, aged from 14 to 17 years. The results show that individuals who fail a subject

OPEN ACCESS

Edited by:

José Carlos Núñez, University of Oviedo, Spain

Reviewed by:

Juan Luis Castejon

University of Alicante, Spain

David Álvarez-García,

University of Oviedo, Spain

${ }^{*}$ Correspondence: María Del Carmen Pérez Fuentes mpf421@ual.es

Specialty section

This article was submitted to

Educational Psychology,

a section of the journal

Frontiers in Psychology

Received: 19 August 2016 Accepted: 14 September 2016

Published: 17 October 2016

Citation:

Molero Jurado MDM, Pérez Fuentes MDC, Luque De La Rosa A,

Martos Martínez Á, Barragán Martín $A B$ and Simón Márquez MdM

(2016) Interpersonal Values and

Academic Performance Related to

Delinquent Behaviors.

Front. Psychol. 7:1480.

doi: 10.3389/fpsyg.2016.01480 as well as those who repeat a course present higher means in delinquent behaviors. Repeaters present higher means in the values of recognition and leadership, and non-repeaters in the value stimulation, whereas students who do not fail obtain higher scores in the value benevolence. Students with high levels of recognition, independence, and leadership, as well as students with low levels of conformity and benevolence display significantly higher levels of delinquent behaviors. Lastly, the probability of presenting a high level of delinquent behaviors is greater in individuals with: high independence, high leadership, high recognition, low benevolence, and low conformity.

Keywords: interpersonal values, academic performance, delinquent behaviors, secondary education, adolescence

\section{INTRODUCTION}

The presence of behavior problems during childhood and adolescence is currently a phenomenon causing great concern (Thomas, 2010). These problematic behaviors frequently lead to antisocial and/or delinquent behaviors with negative consequences for the development and psychosocial adjustment of the adolescent (Fuentes et al., 2011; de la Torre et al., 2013; Gázquez et al., 2015a). In spite of the fact that delinquent behavior includes a large variability of manifestations (Martínez and Gras, 2007), course, and prognosis (White and Frick, 2010), there is a consensus among authors about a series of common traits: these behaviors are a threat to the integrity of others, they infringe social and juridical norms, they are notably frequent and intense, and they are a risk for development and they interfere especially in the individual's processes of adaptation (Garaigordobil, 2005; Peña and Graña, 2006; Burt and Donnellan, 2009; Pahlavan and Andreu, 2009). Thus, taking into account the complexity of the construct, we could refer to a continuum that begins with problem behaviors, passing through antisocial behavior, and ending with delinquent behaviors, of greater severity and social scope.

One of the topics that has received the most attention in the study of delinquent behavior is the analysis of the factors that intervene in the origin and maintenance of this type of 
attitudinal/behavioral repertories. The more traditional hypotheses point toward certain personal variables as the main triggers of delinquent behavior. In the same vein are the notable contributions like that of Patrick et al. (2009), which refer to two personality dimensions (Impulsivity/Emotional insensitivity) that could be directly related to the presence of severe behavior problems and participation in delinquent actions (Lynam et al., 2009). The presence of psychopathic personality traits has also been indicated as one of the triggering factors of severe patterns of antisocial/delinquent behavior in children and adolescents (López-Romero et al., 2011). In other cases, sensation seeking is proposed as one of the characteristic traits of adolescent personality that, along with the lack of control of impulses, favors the subject's involvement in risk behaviors (Peach and Gaultney, 2013; Pérez-Fuentes et al., 2015). According to Harden et al. (2012), this adolescent tendency to seek sensations is mainly due to changes in personality, explained by genetic factors. Thus, changes in sensation seeking would partially explain a greater proclivity to delinquency during adolescence.

In spite of studies that separately analyze the factors involved in the origin of delinquent behavior, the current tendency is based on a multidimensional and dynamic approach, in which the proposed variables must be considered as part of a compendium and in continuous interaction (Muñoz and Navas, 2004). Thus, we found works analyzing the relation between emotional intelligence and aggressiveness (Inglés et al., 2014), behavior problems (Siu, 2009), and antisocial and delinquent behaviors (Garaigordobil and Oñederra, 2010).

On the other hand, authors like Van der Graaff et al. (2012) point to the moderating role of empathy in the perception of parents' support and their children's performing delinquent actions. These authors found that adolescents with lower empathy had a more negative perception of the support received from their parents and they presented a greater number of delinquent behaviors.

Parenting styles and the characteristics of family relations may be the elements that have received the most attention in the analysis of problem behaviors, either as risk or protection factors (Martínez et al., 2013). In any case, the efficacy of the interventions reveals the importance of family factors as a cause of and/or solution to this problem (Tolan et al., 2013). Concerning the family context, report that children's exposure to episodes of domestic violence and frequent conflicts between the parents is related to the onset of aggressive and delinquent behavior in adolescence. Likewise, other noteworthy works on attachment and delinquent behavior (Sousa et al., 2011) indicate that the establishment of stronger ties with the parents predicts a lower risk of delinquent behavior in adolescence, regardless of the degree of exposure to violent episodes during childhood. In other cases, interest is drawn to the study of the effects of parental control (Harris-McKoy and Cui, 2013) and the use of discipline (Lansford et al., 2011), as key aspects in the origin and maintenance of delinquent behaviors in adolescents.

In the school setting, in addition to the presence of delinquent behaviors, the increasing frequency of academic failure is another concern (Pérez-Fuentes et al., 2011). Many authors
(Briggs-Gowan and Carter, 2008; Gázquez and Pérez-Fuentes, 2010; Preddy and Fite, 2012), coincide in relating involvement in delinquent actions to low academic performance, leading to failure, and school dropout (Henry et al., 2012). In this regard, the self-concept as a correlation of social adaptation in adolescence (Fuentes et al., 2011; Álvarez et al., 2015) plays an essential role. Jiménez et al. (2007) found that a positive academic selfconcept fulfills a protector function against the development of delinquent behaviors. Likewise, authors like Nakamoto and Schwartz (2010) state that involvement in violent episodes will have a negative effect on academic performance. Ma et al. (2009) note that aggressors perceive their competences as being more impaired and, therefore, they obtain worse academic results. On the other hand, the expectations of self-efficacy and the academic goals give rise motivational profiles (Valle et al., 2015) and may be detrimental to academic performance, in the cases involving aggressors.

Problems relating to the peer group can derive in academic difficulties, the development of violent interactions in childhood, or the amplification of behavior problems in adolescence (Dishion and Tipsord, 2011). At this point, especially during adolescence, the processes of peer influence determine psychosocial adjustment and the acquisition of certain interpersonal values that will guide relations with the peer group (Paciello et al., 2013; Gázquez et al., 2015b). According to Knecht et al. (2010), adolescents select other group members as friends as a function of the level of similarity in interpersonal values. Therefore, processes of influence and adaptation of antisocial/delinquent behavior among its members will take place in the peer group.

In addition, both in the family context and in the peer group, the acquisition of certain interpersonal values-positively or negatively related to delinquent behavior-is implied, an aspect that the present study attempts to examine. Recently, others proposals show the predictive value of social support in the emotional intelligence of adolescents (Azpiazu et al., 2015).

On the other hand, the time dedicated by adolescents to the use of internet and inappropriate videogames has been related to the acquisition and change in the values of youth, and may be associated with a higher probability of delinquent activities (Holtz and Appel, 2011). This is why more attention has been paid in recent years to the variables that make the onset of antisocial behaviors less likely (Inglés et al., 2015) or that attenuate their manifestations after they have emerged (Loeber and Farrington, 2012). Thus, attitudes and values, such as social sensitivity, prosocial leadership, or safety in interpersonal relations, have been related to competence and adequate social adaptation in adolescents (Jiménez and López-Zafra, 2011).

Lastly, in order to provide greater clarity in this regard, we present this work, which will attempt, on the one hand, to analyze the influence of academic performance (measured as failing a subject or repeating a course) on delinquent behaviors and interpersonal values (Hypothesis $1=$ Poor academic performance is associated with a greater presence of delinquent behavior). On the other hand, it also analyzes the relation between high or low scores in interpersonal values and the presence of delinquent behaviors in secondary education 
students (Hypothesis 2 = Subjects with high levels of recognition, independence and leadership, and low levels of conformity and benevolence, have higher levels of delinquent behavior). Lastly, we wish to analyze the degree to which interpersonal values fulfill a protective function against delinquent behaviors in secondary education, as well as the interaction of academic performance with interpersonal values and its impact on the presence of delinquent behaviors (Hypothesis ${ }_{3}=$ The presence of high levels in some interpersonal values such as benevolence, exert a protective function against delinquent behavior, with a mediator effect of academic performance).

\section{MATERIALS AND METHODS}

\section{Participants}

The initial sample was made up of 1055 students from the $3 \mathrm{rd}$ and 4th grade of Compulsory Secondary Education (CSE) of Almeria province (Spain), of whom 120 (11.37\%) were eliminated because they were aliens and had not completed the questionnaires in time due to their lack of mastery of the Spanish language; additionally, due to errors or omissions, or to not having attended one of the two administration sessions, another 50 (4.74\%) subjects were excluded. The final sample was made up of 885 students of CSE, of whom $49.8 \%(n=441)$ were male and $50.2 \%$ ( $n=444$ ) were female, with age ranging from 14 to 18 years, mean age of 15.2 years $(S D=0.90)$ for the total sample, and 15.22 years $(S D=0.92)$ and 15.19 years $(S D=0.89)$ for males and females, respectively.

The distribution of the sample as a function of having failed a subject was as follows: those who failed a subject ( $n=729 ; 377$ males and 352 females) and those who did not fail $(n=156$; 64 males and 92 females). The chi-square test of homogeneity of the frequency distribution, $c_{(1885)}^{2}=5.87, p=0.02$, revealed statistical differences between the four groups made up of the variables Gender and Failing. However, regarding the variable repeating a course: Repeaters $(n=273 ; 139$ males and 134 females) and Non-repeaters $(n=612 ; 302$ males and 310 females). In this case, no statistical differences were observed among the four groups made up of the variables Gender and Repeating, $\mathrm{c}_{(1885)}^{2}=0.19, p=0.67$.

To obtain the sample, we used random cluster sampling, attending to the different geographical areas of the province of Almeria (center, east, and west). Each area had at least one public school, with the sample of each area always exceeding 200 students [center 212 subjects (24\%), east 333 subjects (37.6\%), and west 340 subjects (38.4\%)], four classes in each school (two classes of 3 rd grade and two of 4 th grade).

\section{Instruments}

\section{Academic Performance}

This was measured with the items: Did you ever fail a subject? Have you ever repeated a course? In both cases, the response options were YES/NO.

\section{Interpersonal Values Questionnaire (Gordon, 1977)}

This 90-item instrument has two response options (YES-NO) and analyzes six aspects of the individual's relationship with others: Stimulation, Conformity, Recognition, Independence, Benevolence, and Leadership.

\section{Antisocial-Delinquent Behaviors-Questionnaire (Seisdedos, 1995)}

This includes a total of 40 items that assess antisocial (entering a forbidden place, throwing rubbish on the floor) and delinquent behaviors (using drugs, stealing, etc.).

Internal consistency was analyzed by the coefficient KuderRichardson (KR-20) for each of the scales of Interpersonal Values Questionnaire $\left(\mathrm{K}-\mathrm{R} 20_{\mathrm{S}}=0.74 ; \mathrm{K}-\mathrm{R} 20_{\mathrm{C}}=0.81 ; \mathrm{K}-\mathrm{R} 20_{\mathrm{R}}=\right.$ $\left.0.77 ; \mathrm{K}-\mathrm{R} 20_{\mathrm{I}}=0.81 ; \mathrm{K}-\mathrm{R} 20_{\mathrm{B}}=0.85 ; \mathrm{K}-\mathrm{R} 20_{\mathrm{L}}=0.78\right)$, and scale of criminal behavior of Antisocial-Delinquent Behaviors Questionnaire $\left(\mathrm{K}-\mathrm{R} 20_{\mathrm{ADd}}=0.87\right)$. In general, the internal consistency coefficients obtained for scales in the study sample were high $(>0.70)$, indicating adequate homogeneity among the items of the questionnaires.

\section{Procedure}

We contacted the headmasters and guidance counselors of the selected schools to present the goals of the study and the instruments to be used therein. If they expressed interest in participating, we requested their permission and the necessary collaboration to carry out the study. This study was exempt from ethical approval, because the study did not involve any potential risk for the participants. All participants provided written consent. We held a meeting with the parents and the principal researchers and, after informing the parents, we obtained their consent for their children to participate in the study. We then scheduled the application of the questionnaires. The questionnaires were administered in two 50-min sessions, with a variable resting time between them, separated either by a class and a recess, or simply a recess, with more than $20 \mathrm{~min}$ between sessions. The questionnaires were administered collectively in the classroom or in one of the spaces of the school if various classes were grouped together. The questionnaires were voluntary and anonymous.

\section{Data Analysis}

For the present study, we used a cross-sectional, descriptive, and correlational design in order to determine the relations between interpersonal values (stimulation, conformity, recognition, independence, benevolence, and leadership) and delinquent behaviors, as well as the relationship between these two aspects with the subjects' academic performance, measured as a function of having failed a subject and having repeated a course (failing and repeating).

After the normal distribution of all the SIV scales (Gordon, 1977) had been determined, we identified the criterion to define the thresholds (high and low) of the sample on these scales. Thus, the total sample of subjects $(N=885)$ was divided into two groups for each one of the scales: (a) students with low scores on Stimulation, Conformity, Recognition, Independence, Benevolence, and Leadership, that is, who obtained scores equal to or lower than percentile 25 (scores equal to or higher than $14,11,8,13,14$, and 7 , respectively; $n_{2 \mathrm{~S}}=233 ; 26.3 \% ; n_{2 \mathrm{C}}$ $=235 ; 26.6 \% ; n_{2 \mathrm{~A}}=218 ; 24.6 \% ; n_{2 \mathrm{I}}=237 ; 26.8 \% ; n_{2 \mathrm{~B}}$ 
$=262 ; 29.6 \% ; n_{2 \mathrm{~L}}=240 ; 27.1 \%$ ); (b) students with high scores on Stimulation, Conformity, Recognition, Independence, Benevolence, and Leadership, that is, who obtained scores equal to or higher than percentile 75 (scores equal to or higher than $20,19,15,21,22$, and 14 , respectively) $\left(n_{1 \mathrm{~S}}=291 ; 32.9 \% ; n_{1 \mathrm{C}}=\right.$ $227 ; 25.6 \% ; n_{1 \mathrm{~A}}=238 ; 26.9 \% ; n_{1 \mathrm{I}}=268 ; 30.3 \% ; n_{1 \mathrm{~B}}=248 ; 28 \%$; $\left.n_{1 \mathrm{~L}}=246 ; 27.8 \%\right)$.

We used Student's $t$-test to analyze the differences between individuals with high and low scores on the SIV Questionnaire scales, between students who had/had not failed, as well as between students who had/had not repeated a course, regarding delinquent behavior. To determine the magnitude of the effect size of the significant differences yielded by the $t$-test, we used Cohen's $d$ index, the interpretation of which is: $d \leq 0.50$ indicates a small effect size; $d \leq 0.79$ indicates a medium effect size; and $d \geq 0.80$ indicates a large effect size.

In order to analyze the predictive capacity of interpersonal values and academic performance on delinquent behaviors, we performed binary logistic regression analysis, using the forward stepwise regression procedure based on Wald's statistic. Thus, the six predictor variables (stimulation, conformity, recognition, independence, benevolence, and leadership) and the criterion variable (delinquent behavior) were divided as a function of high and low thresholds, maintaining for the predictor variables the one used in the previous test. Regarding the predictor variables failing and repeating, it was not necessary to establish any threshold because the students were grouped as a function of whether or not they had that characteristic. To classify the sample according to delinquent behavior, we followed the same criterion as with the SIV Questionnaire, dividing the sample into subjects with high and low scores as follows: (a) subjects scoring high in delinquent behavior were those who scored equal to or higher than percentile 75 (scores equal to or higher than $3 ; N_{1}=247$; $27.9 \%$ ); (b) subjects with low scores in delinquent behavior were those who scored equal to or lower than percentile 25 (scores equal to $0 ; N_{2}=373 ; 42.1 \%$ ).

This model allows determining the probability of occurrence of a certain fact or event (e.g., aggressive behavior) in the presence one or various predictors (e.g., high scores in stimulation, conformity, recognition, independence, benevolence, and leadership, failing, or repeating) using the Odds Ratio (OR) statistic to estimate this probability both in the total sample and in the sample as a function of the variables gender, failing, and repeating.

TABLE 1 | Difference of means in delinquent behaviors and interpersonal values in students who had not and who had failed.

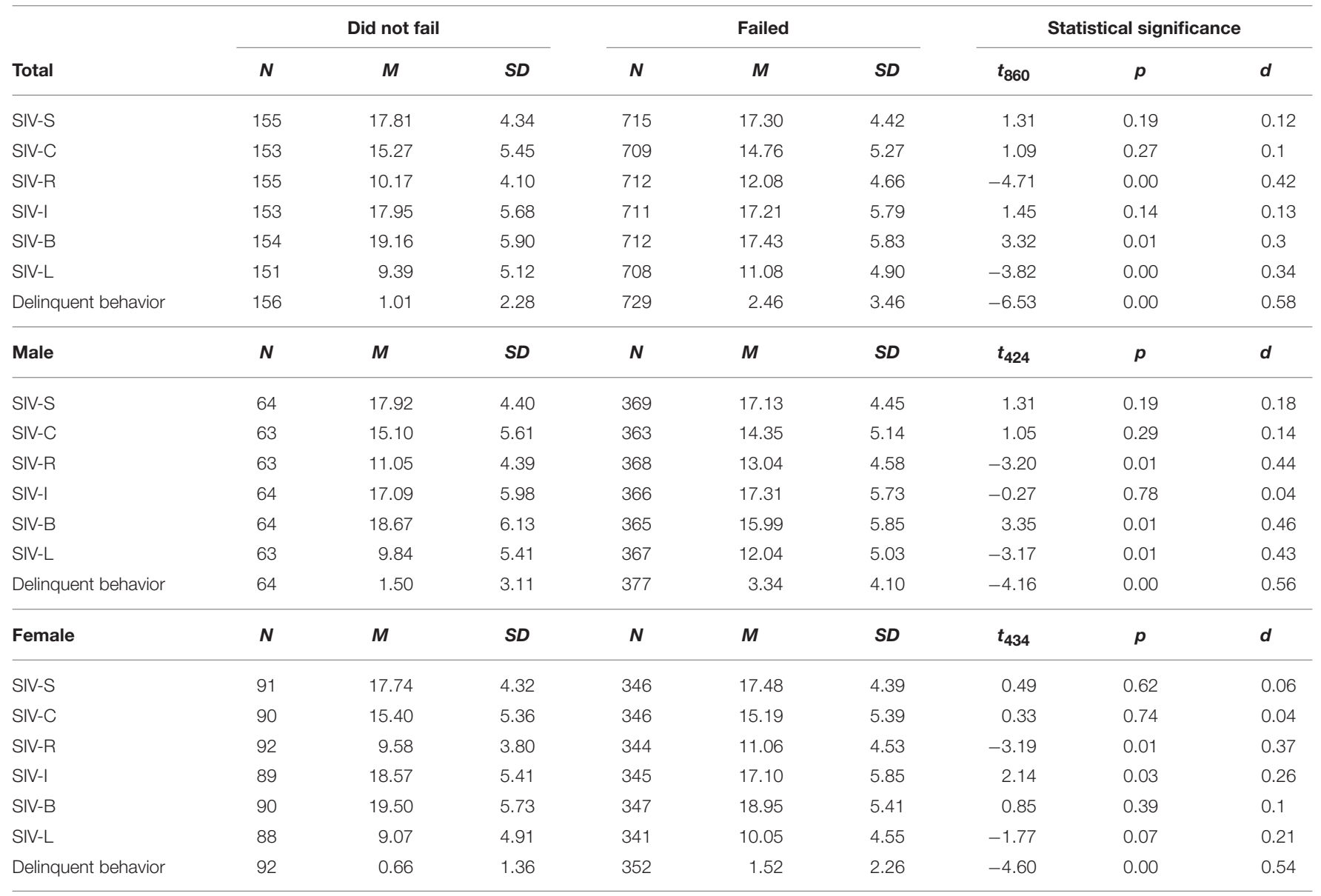

SIV-S, Stimulus; SIV-C, Conformity; SIV-R, Acknowledgement; SIV-I, Independence; SIV-B, Benevolence; SIV-L, Leadership. 
TABLE 2 | Difference of means in delinquent behaviors values and interpersonal values in repeater and non-repeater students.

\begin{tabular}{|c|c|c|c|c|c|c|c|c|c|}
\hline \multirow[b]{2}{*}{ Total } & \multicolumn{3}{|c|}{ Non-repeaters } & \multicolumn{3}{|c|}{ Repeaters } & \multicolumn{3}{|c|}{ Statistical significance } \\
\hline & $N$ & $M$ & $S D$ & $N$ & $M$ & $S D$ & $t_{860}$ & $p$ & $d$ \\
\hline SIV-S & 600 & 17.79 & 4.42 & 270 & 16.51 & 4.27 & 3.99 & 0.00 & 0.29 \\
\hline SIV-C & 594 & 14.85 & 5.39 & 268 & 14.86 & 5.12 & -0.03 & 0.98 & 0 \\
\hline SIV-R & 599 & 11.66 & 4.60 & 268 & 11.91 & 4.66 & -0.75 & 0.45 & 0.05 \\
\hline SIV-I & 596 & 17.29 & 5.79 & 268 & 17.45 & 5.75 & -0.37 & 0.71 & 0.03 \\
\hline SIV-B & 600 & 17.85 & 5.94 & 266 & 17.48 & 5.74 & 0.86 & 0.39 & 0.06 \\
\hline SIV-L & 592 & 10.35 & 5.10 & 267 & 11.75 & 4.56 & -3.84 & 0.00 & 0.28 \\
\hline Delinquent behavior & 612 & 1.82 & 2.96 & 273 & 3.06 & 3.91 & -4.65 & 0.00 & 0.38 \\
\hline Male & $N$ & $M$ & $S D$ & $N$ & $M$ & $S D$ & $t_{424}$ & $p$ & $d$ \\
\hline SIV-S & 296 & 17.68 & 4.44 & 137 & 16.32 & 4.33 & 2.98 & 0.01 & 0.31 \\
\hline SIV-C & 291 & 14.32 & 5.39 & 135 & 14.76 & 4.80 & -0.82 & 0.41 & 0.08 \\
\hline SIV-R & 295 & 12.66 & 4.72 & 136 & 12.93 & 4.33 & -0.56 & 0.57 & 0.06 \\
\hline SIV-I & 296 & 17.31 & 5.89 & 134 & 17.19 & 5.50 & 0.21 & 0.83 & 0.02 \\
\hline SIV-B & 295 & 16.40 & 6.14 & 134 & 16.38 & 5.60 & 0.03 & 0.97 & 0 \\
\hline SIV-L & 294 & 11.42 & 5.33 & 136 & 12.36 & 4.64 & -1.77 & 0.07 & 0.18 \\
\hline Delinquent behavior & 302 & 2.56 & 3.69 & 139 & 4.18 & 4.47 & -3.73 & 0.00 & 0.41 \\
\hline Female & $N$ & $M$ & $S D$ & $N$ & $M$ & $S D$ & $t_{434}$ & $p$ & $d$ \\
\hline SIV-S & 304 & 17.90 & 4.40 & 133 & 16.71 & 4.22 & 2.64 & 0.01 & 0.27 \\
\hline SIV-C & 303 & 15.36 & 5.35 & 133 & 14.95 & 5.45 & 0.72 & 0.47 & 0.08 \\
\hline SIV-R & 304 & 10.69 & 4.26 & 132 & 10.87 & 4.78 & -0.39 & 0.69 & 0.04 \\
\hline SIV-I & 300 & 17.27 & 5.69 & 134 & 17.71 & 6.00 & -0.73 & 0.46 & 0.08 \\
\hline SIV-B & 305 & 19.26 & 5.38 & 132 & 18.60 & 5.69 & 1.16 & 0.24 & 0.12 \\
\hline SIV-L & 298 & 9.29 & 4.64 & 131 & 11.11 & 4.41 & -3.81 & 0.00 & 0.4 \\
\hline Delinquent behavior & 310 & 1.11 & 1.73 & 134 & 1.89 & 2.80 & -2.99 & 0.01 & 0.37 \\
\hline
\end{tabular}

SIV-S, Stimulus; SIV-C, Conformity; SIV-R, Acknowledgement; SIV-I, Independence; SIV-B, Benevolence; SIV-L, Leadership.

Lastly, to analyze conjointly the scores of the subgroups derived from the interaction of the predictor variables (failing, repeating, and interpersonal values), we carried out a two-factor ANOVA with interaction.

\section{RESULTS}

\section{Delinquent Behaviors and Interpersonal Values As a Function of Failing and Repeating}

Observing the mean scores for delinquent behavior and the different interpersonal values as a function of the variable failing, students who had failed a subject presented significantly higher mean scores in delinquent behaviors, recognition, and leadership, with small effect sizes $(d \leq 0.50)$, except for delinquent behaviors, where the effect was medium $(d=0.58)$. On the other hand, significantly higher scores were only found in the value benevolence for students who had never failed and, again in this case, the effect of the variable failing was small $(d=0.30)$.

When addressing gender, we observed that the same results were repeated in the groups of males and females, except that for the females, no differences were found in the mean score of the value leadership (see Table 1).
The analysis of the mean scores of interpersonal values and delinquent behaviors as a function of repeating/not repeating a course (see Table 2) revealed significantly higher scores in leadership and delinquent behaviors for repeaters, with a small effect for the variable repeating in both cases $(d \leq 0.50)$, whereas non-repeaters presented significantly higher scores in stimulation, also with a small effect for the variable repeating ( $d$ $=0.29$ ). The same thing occurred in the analysis as a function of gender in the group of males and females, except that in the males, no differences in the mean scores of leadership were obtained.

\section{Delinquent Behaviors in Students with High and Low Scores in Interpersonal Values}

Table 3 presents the differences in the presence of delinquent behaviors between students with high and low scores in the diverse SIV scales, in the total sample, as well as according to gender, failing, and repeating a course. For the total sample, all the scales presented significant differences except for the value stimulation. Thus, students with high levels of recognition, independence, and leadership showed significantly higher levels of delinquent behaviors, with a small effect size of the values recognition and leadership ( $d=0.28$ and $d=0.49$, respectively), whereas the effect size of the value independence was medium $(d$ 
TABLE 3 | Difference of means in delinquent behaviors in students low and high levels in interpersonal values.

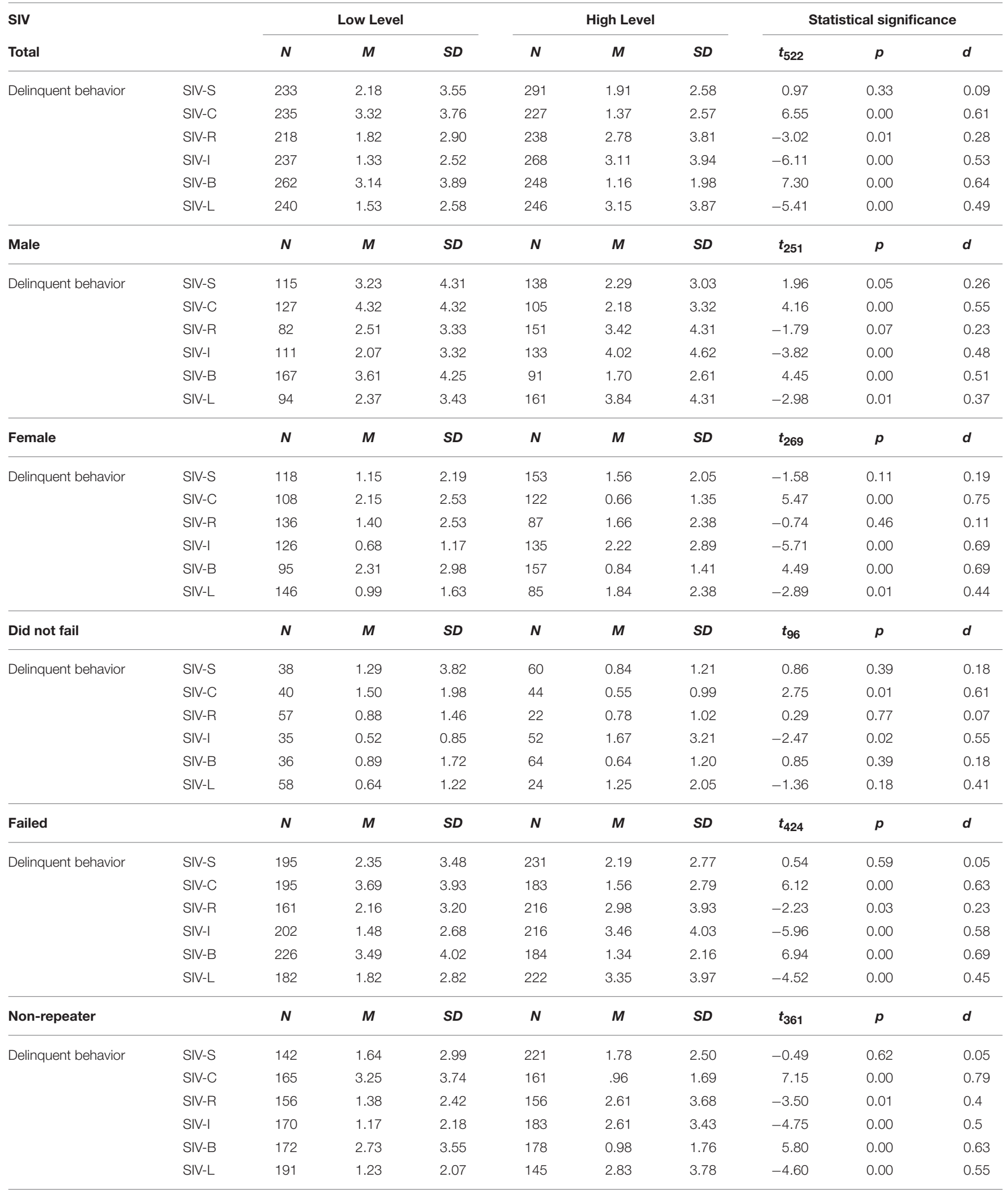


TABLE 3 | Continued

\begin{tabular}{|c|c|c|c|c|c|c|c|c|c|c|}
\hline \multirow{2}{*}{$\begin{array}{l}\text { SIV } \\
\text { Repeater }\end{array}$} & & \multicolumn{3}{|c|}{ Low Level } & \multicolumn{3}{|c|}{ High Level } & \multicolumn{3}{|c|}{ Statistical significance } \\
\hline & & $N$ & $M$ & $S D$ & $N$ & $M$ & $S D$ & $t_{159}$ & $p$ & $d$ \\
\hline \multirow[t]{6}{*}{ Delinquent behavior } & SIV-S & 91 & 3.01 & 4.16 & 70 & 2.30 & 2.82 & 1.29 & 0.19 & 0.2 \\
\hline & SIV-C & 70 & 3.50 & 3.82 & 66 & 2.36 & 3.81 & 1.74 & 0.08 & 0.3 \\
\hline & SIV-R & 62 & 2.94 & 3.65 & 82 & 3.09 & 4.06 & -0.23 & 0.81 & 0.04 \\
\hline & SIV-I & 67 & 1.75 & 3.20 & 85 & 4.19 & 4.71 & -3.80 & 0.00 & 0.6 \\
\hline & SIV-B & 90 & 3.91 & 4.37 & 70 & 1.60 & 2.41 & 4.25 & 0.00 & 0.64 \\
\hline & SIV-L & 49 & 2.72 & 3.79 & 101 & 3.60 & 3.98 & -1.30 & 0.19 & 0.23 \\
\hline
\end{tabular}

SIV-S, Stimulus; SIV-C, Conformity; SIV-R, Acknowledgement; SIV-I, Independence; SIV-B, Benevolence; SIV-L, Leadership.

$=0.53)$. Students with low levels of conformity and benevolence displayed significantly higher levels of delinquent behaviors, in both cases with a medium effect size of both values $(d \geq 0.50)$.

In the analysis as a function of gender, we observed that males and females with high levels of independence and leadership both presented significantly higher mean levels of delinquent behaviors, with a small effect size in all cases $(d \leq 0.50)$, except for the females in the value independence, where the effect of delinquent behaviors was medium $(d=0.69)$.

Regarding the variable failing, as in the total sample, the students who had failed and who presented high levels in recognition, independence, and leadership also displayed significantly levels higher in antisocial behaviors with a small effect size $(d \leq 0.50)$, except for the value independence, where the effect was medium $(d=0.58)$. In the group of students who did not fail, only the value independence had an effect on delinquent behaviors, with a medium effect $(d=$ 0.58 ); the mean level of delinquent behaviors was statistically higher among students with high levels of independence. In the group of students who had failed, those with low levels of conformity and benevolence obtained significantly higher mean scores in antisocial behaviors, with a medium effect size for both values $(d \geq 0.50)$. This same result was observed in the group of students who did not fail, but only for the value conformity, with a medium effect of this value on delinquent behavior.

Lastly, with regard to repeating a course, non-repeaters who scored high on the scales of recognition, independence, and leadership also obtained significantly higher mean levels of delinquent behaviors, with effect sizes of $d=0.40, d=0.50$, and $d=0.55$, respectively. This effect was also observed for the value independence among repeaters. Likewise, non-repeaters with low levels of conformity and benevolence presented higher mean levels of delinquent behaviors, with a medium effect size for both values $(d \geq 0.50)$. This same relation was observed among repeaters between the value benevolence and delinquent behaviors, with the same effect size as in the nonrepeaters.

\section{Do Interpersonal Values Predict Delinquent Behaviors?}

Table 4 presents the probability of presenting high levels of delinquent behavior derived from the binary logistic regression in the total sample, considering the variables gender, failing, and repeating. The correct percentages of classification ranged between 57.4 and $69.8 \%$ for recognition and conformity, respectively. Regarding gender, for males, the correct classification ranged from $57.7 \%$ for the factor leadership to $67.4 \%$ for the factor conformity. With regard to the females, the correct classification ranged between $71.6 \%$ for independence and $74.4 \%$ for conformity. Concerning failing, the percentages for those who had failed a subject ranged from $62.2 \%$ for leadership to $70.6 \%$ for conformity, but recognition did not enter the model. In the group of students who had never failed, the correct percentages ranged from $80.3 \%$ for independence to $81.4 \%$ for conformity. In the analysis of the groups of repeaters and non-repeaters, the levels of correct classification ranged between $64 \%$ for recognition and $72.1 \%$ for conformity. In the group of repeaters, the correct classification ranged from $72.6 \%$ for the factor independence to $69.6 \%$ for the factor benevolence. Nagelkerke's $R^{2}$ ranged between 0.02 for the females in the factor leadership and 0.28 for the non-repeaters in the factor conformity.

The analysis and interpretation of the OR data obtained in total sample indicate that the probability of presenting high levels of delinquent behavior is: (a) 4.58 times higher in students with high independence, (b) 3.34 times higher in students with high leadership, (c) 1.77 times higher in students with high recognition, (d) 0.21 times lower in students with high benevolence, and (e) 0.18 times lower in students with high conformity.

In the analysis as a function of gender and the variables failing and repeating, the probability of presenting high levels of delinquent behavior is: (a) 0.24 (males), 0.11 (females), 0.21 (NOT failing), 0.17 (Failing), and 0.11 (Nonrepeater) times lower in students with high conformity; (b) 0.07 (Non-repeater) times higher in students with high recognition; (c) 3.14 (males), 7.45 (females), 0.24 (NOT failing), 5.33 (Failing), 4.08 (Non-repeater), and 7 (Repeater) times higher in students with high independence; (d) 0.36 (males), 0.16 (females), 0.28 (Failing), 0.20 (Non-repeater), and 0.20 (Repeater) times lower in students with high benevolence; and (e) 1.09 (males), 0.03 (females), 2.82 (Failing), and 3.25 (Non-repeater) times higher in students with high leadership. 
TABLE 4 | Logistic regression of the probability of high delinquent behaviors.

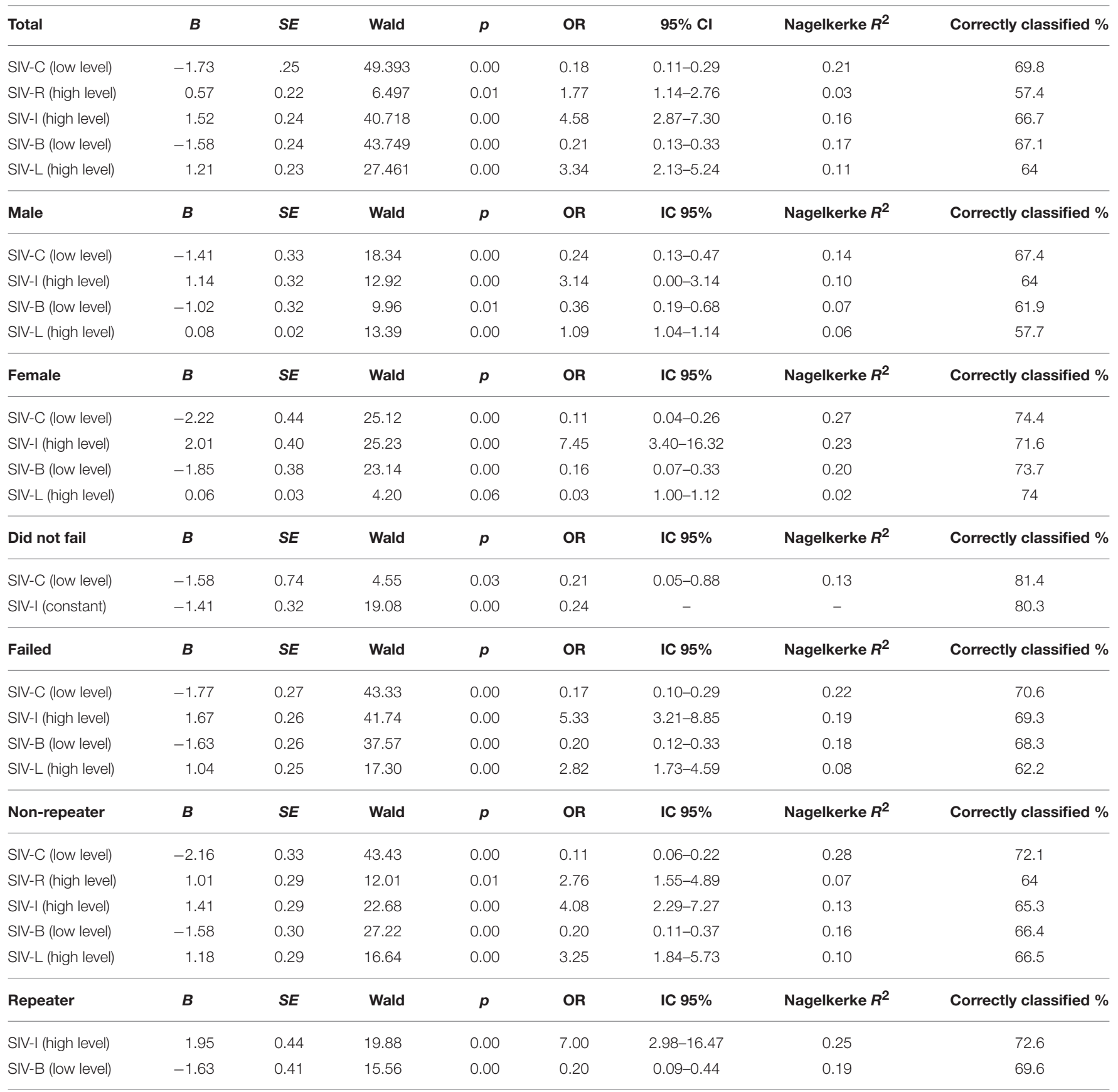

SIV-S, Stimulus; SIV-C, Conformity; SIV-R, Acknowledgement; SIV-I, Independence; SIV-B, Benevolence; SIV-L, Leadership; B, coefficient; CI, 95\% confidence interval.

\section{Interpersonal Values Predicting Delinquent Behaviors: with and without Interaction with the Variables Failing and Repeating}

We analyzed the scores obtained in the five factors as a function of both variables (failing and repeating), by means of a two-factor ANOVA with interaction, obtaining a significant interaction only between the factor benevolence and the variable failing, $F_{(1,509)}$ $=7.4, p=0.01, R^{2}=0.13$, as shown in Figure 1 .

\section{DISCUSSION}

With regard to the first goal of this study, we note that the students who failed and the repeaters present higher means of delinquent behaviors, both in males and in females, with a medium effect of the variable failing $(d \leq 0.79)$, and a small effect for the variable repeating $(d \leq 0.50)$, respectively. These results are in line with those found by other studies relating low academic performance with delinquent actions (Briggs-Gowan 


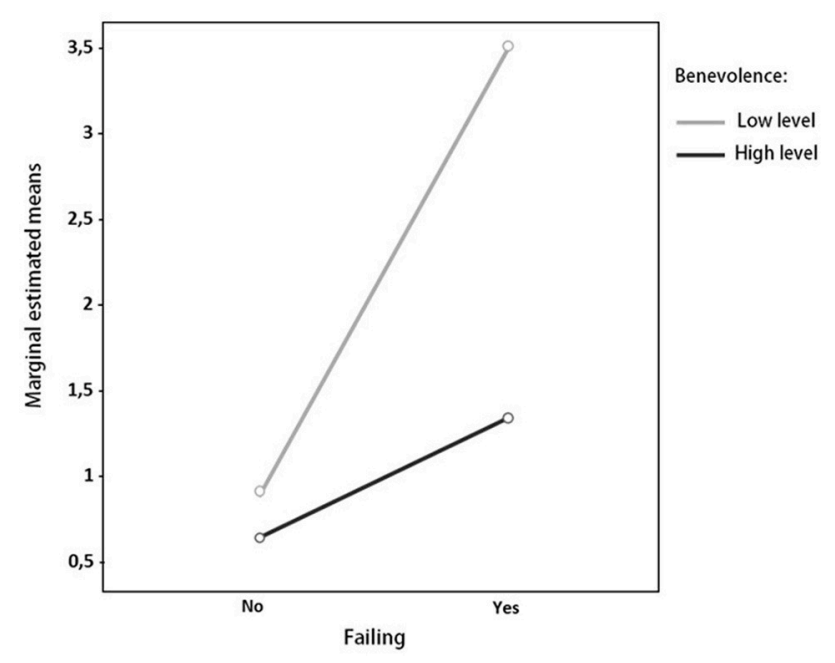

FIGURE 1 | Two-factor ANOVA with interaction: Failing and interpersonal value benevolence.

and Carter, 2008; Gázquez and Pérez-Fuentes, 2010; Preddy and Fite, 2012).

Not only students who fail, but also the repeaters present higher means in the values of recognition, as well as in the value of leadership. These differences are maintained in the groups of males and females who fail a subject, but only for the value recognition, with a small effect size $(d \leq 0.50)$. On the other hand, students who had not failed obtained higher scores in the value benevolence, and non-repeaters in the value stimulation, with small effects $(d \leq 0.50)$ of both variables, failing and repeating, respectively. Whereas in other studies, the value leadership is understood as prosocial leadership and is related to competence and social adaptation in adolescents (Jiménez and López-Zafra, 2011), in our study, leadership has a negative interpretation in the questionnaire that assesses it, because it refers to exerting authority over other people, that is, a position of control or power. Therefore, it may be appropriate to use another type of instrument that would allow us to measure this value positively in order to analyze the influence of prosocial leadership on adolescents' delinquent behavior.

The results achieved for our second goal reveal that students with high levels of recognition, independence, and leadership show significantly higher levels of delinquent behaviors, regardless of the variables failing and repeating and of gender concerning independence and leadership. Moreover, students with low levels of conformity and benevolence obtained significantly higher levels of delinquent behaviors, regardless of the variables failing and repeating. That is, individuals who like to be acknowledged, admired and approved of by others; who

\section{REFERENCES}

Álvarez, A., Suárez, N., Tuero, E., Núñez, J. C., Valle, A., and Regueiro, B. (2015). Implicación familiar, autoconcepto del adolescente y rendimiento académico use their own criteria to decide what they have a right to do; who exert authority and power over others; who do not follow socially correct or appropriate norms or rules; and who are not very generous and do not help others-all these individuals present higher levels of delinquent behaviors.

Lastly, with regard to the third goal, the probability of presenting a high level of delinquent behavior is greater among students with: high independence, high leadership, high recognition, low benevolence, and low conformity. These five negative predictors should be the target of intervention in order to eliminate delinquent behavior.

Ultimately, we note the great importance of the interaction of benevolence and failing, which, when levels of benevolence are low and the student has failed some subject, leads to a considerable increase in delinquent behavior.

A limitation of this study is the sample, which, although representative, only included students from secondary education. A possible goal of future research is to carry out this same study with higher educational levels or in non-regulated studies, to determine whether the influence of interpersonal values on delinquent behaviors changes or remains the same.

Therefore, although the present study presents some limitations to be taken into account in future studies, it can be considered a precursor in a new line of research to clarify the relation between delinquent behavior and violence, adding to the diverse studies that have not clarified the relation between them. It may also be of great interest to the educational community because it contributes relevant data for the design of interventions promoting protector factors and reducing risk factors, for example, in the peer group (Knecht et al., 2010; Paciello et al., 2013). It is also of interest to parents and in order to elaborate programs targeting the parents, because, as indicated, family factors are highly involved in the origin of adolescents' delinquent behaviors (Martínez et al., 2013; Tolan et al., 2013).

\section{AUTHOR CONTRIBUTIONS}

The authors incorporated worked with AMM and ABBM in the literature search. The distribution of tasks would be as follows: MMJ and MCPF (Drafting and analysis of data). AMM, ABBM, and MMSM (bibliographic search). ALR Helped in the realization of the changes requested by the reviewer).

\section{FUNDING}

This work is the result of Research Project P08-SEJ-04305, cofinanced by the Consejería de Innovación, Ciencia y Empresa (Council of Innovation, Science and Enterprise) of the Junta of Andalucía and FEDER. 
support on emotional intelligence in adolescence]. Eur. J. Educ. Psychol. 8, 23-29. doi: 10.1016/j.ejeps.2015.10.003

Briggs-Gowan, M. J., and Carter, A. S. (2008). Social-emotional screening status in early childhood predicts elementary school outcomes. Pediatrics 121, 957-962. doi: $10.1542 /$ peds.2007-1948

Burt, S., and Donnellan, M. (2009). Development and validation of the subtypes of antisocial behavior questionnaire. Aggress. Behav. 35, 376-398. doi: $10.1002 / \mathrm{ab} .20314$

de la Torre, M. J., Casanova, P. F., Villa Carpio, M., and Cerezo, M. (2013). Consistencia e inconsistencia parental: relaciones con la conducta agresiva and satisfacción vital de los adolescentes [Perceived interparental-consistency: relationships between aggressive behavior and life satisfaction in adolescents]. Eur. J. Educ. Psychol. 6, 135-149. doi: 10.1989/ejep.v6i2.112

Dishion, T. J., and Tipsord, J. M. (2011). Peer contagion in child and adolescent social and emotional development. Ann. Rev. Psychol. 62, 189-214. doi: 10.1146/annurev.psych.093008.100412

Fuentes, M. C., García, J. F., Gracia, E., and Lila, M. (2011). Autoconcepto y ajuste psicosocial en la adolescencia [Self-concept and psychosocial adjustment in adolescence]. Psicothema 23, 7-12.

Garaigordobil, M. (2005). Conducta antisocial durante la adolescencia: correlatos socioemocionales, predictores y diferencias de género [Antisocial behavior in adolescence: socioemotional correlates, predictors, and gender differences]. Psicol. Conduct. 13, 197-215.

Garaigordobil, M., and Oñederra, J. A. (2010). Inteligencia emocional en las víctimas de acoso escolar $\mathrm{y}$ en los agresores [Emotional intelligence in the victims of bullying and in the aggressors]. Eur. J. Educ. Psychol. 3, 243-256. doi: $10.1989 /$ ejep.v3i2.63

Gázquez, J. J., and Pérez-Fuentes, M. C. (2010). "School violence and academic performance: instrument to diagnose performance profiles associated with violence in schools," in School Coexistence. Psychological and Educational Aspects, eds J. J. Gázquez and M. C. Pérez-Fuentes (Granada: GEU), 333-338.

Gázquez, J. J., Pérez-Fuentes, M. C., Carrión, J. J., Luque, A., and Molero, M. M. (2015a). Perfiles de valores interpersonales y análisis de conductas y actitudes sociales de adolescentes [Interpersonal value profiles and analysis to adolescent behavior and social attitudes]. Rev. Psicodidáctica 20, 321-337. doi: 10.1387/RevPsicodidact.12978

Gázquez, J. J., Sainz, J., Pérez-Fuentes, M. C., Molero, M. M., and Soler, F. J. (2015b). Interpersonal value profiles and analysis of adolescent academic performance and social thinking. Front. Psychol. 6:575. doi: 10.3389/fpsyg.2015.00575

Gordon, L. V. (1977). Interpersonal Values Questionnaire (SIV). Madrid: TEA.

Harden, K. P., Quinn, P. D., and Tucker-Drob, E. M. (2012). Genetically influenced change in sensation seeking drives the rise of delinquent behavior during adolescence. Dev. Sci. 15, 150-163. doi: 10.1111/j.1467-7687.2011. 01115.x

Harris-McKoy, D., and Cui, M. (2013). Parental control, adolescent delinquency, and young adult criminal behavior. J. Child Fam. Stud. 22, 836-843. doi: 10.1007/s10826-012-9641-x

Henry, K. L., Knight, K. E., and Thornberry, T. P. (2012). School disengagement as a predictor of dropout, delinquency, and problem substance use during adolescence and early adulthood. J. Youth Adolesc. 41, 156-166. doi: 10.1007/s10964-011-9665-3

Holtz, P., and Appel, M. (2011). Internet use and video gaming predict problem behavior in early adolescence. J. Adolesc. 34, 49-58. doi: 10.1016/j.adolescence.2010.02.004

Inglés, C. J., Gonzálvez-Maciá, C., García-Fernández, J. M., Vicent, M. V., and Martínez-Monteagudo, M. C. (2015). Current status of research on school refusal. Eur. J. Educ. Psychol. 8, 37-52. doi: 10.1016/j.ejeps.2015.10.005

Inglés, C. J., Torregrosa, M. S., García-Fernández, J. M., Martínez-Monteagudo, M. C., Estévez, E., and Delgado, B. (2014). Conducta agresiva e inteligencia emocional en la adolescencia [Aggressive behavior and emotional intelligence in adolescence]. Eur. J. Educ. Psychol. 7, 29-41.

Jiménez, M. I., and López-Zafra, E. (2011). Actitudes sociales y adaptación social en adolescentes españoles: el papel de la inteligencia emocional percibida [Social attitudes and social adjustment in Spanish adolescents: the role of perceived emotional intelligence]. Rev. Psicol. Soc. 26, 105-117. doi: $10.1174 / 021347411794078417$
Jiménez, T. I., Murgui, S., Estévez, E., and Musitu, G. (2007). Family communication and delinquent behavior among Spanish adolescents: the mediating role of self-esteem. Rev. Latinoam. Psicol. 39, 473-485.

Knecht, A., Snijders, T. A., Baerveldt, C., Steglich, C. E., and Raub, W. (2010). Friendship and delinquency: selection and influence processes in early adolescence. Soc. Dev. 19, 494-514. doi: 10.1111/j.1467-9507.2009. 00564.x

Lansford, J. E., Criss, M. M., Laird, R. D., Shaw, D. S., Pettit, G. S., Bates, J. E., et al. (2011). Reciprocal relations between parents' physical discipline and children's externalizing behavior during middle childhood and adolescence. Dev. Psychopathol. 23, 225-238. doi: 10.1017/S0954579410000751

Loeber, R., and Farrington, D. P. (2012). Advancing knowledge about direct protective factors that may reduce youth violence. Am. J. Prev. Med. 43, 24-25. doi: 10.1016/j.amepre.2012.04.031

López-Romero, L., Romero, E., and Luengo, M. A. (2011). La personalidad psicopática como indicador distintivo de severidad y persistencia en los problemas de conducta infanto-juveniles [The psychopathic personality as a distinctive indicator of the severity and persistence of child-youth behavior problems]. Psicothema 23, 660-665.

Lynam, D. R., Miller, D. J., Vachon, D., Loeber, R., and Stouthamer-Loeber, M. (2009). Psychopathy in adolescence predicts official reports of offending in adulthood. Youth Violence Juv. J. 7, 189-207. doi: 10.1177/15412040093 33797

Ma, L., Phelps, E., Lerner, J. V., and Lerner, R. M. (2009). Academic competence for adolescents who bully and who are bullied. J. Early Adolesc. 29, 862-897. doi: $10.1177 / 0272431609332667$

Martínez, G., and Gras, M. (2007). La Conducta Antisocial Percibida por Adolescentes de Enseñanza Secundaria Obligatoria: Frecuencia, Contexto $y$ Atribución Causal [Antisocial Behavior Perceived by Adolescents in Secondary Education: Frequency, Context, and Causal Attribution]. Barcelona: Universidad de Barcelona.

Martínez, I., Fuentes, M., García, F., and Madrid, I. (2013). El estilo de socialización familiar como factor de prevención o riesgo para el consumo de sustancias y otros problemas de conducta en los adolescentes españoles [Family socialization style as a prevention or risk factor for substance consumption and other behavior problems in Spanish adolescents]. Adicciones. Rev. Socidrogalcohol. 25, 235-242. doi: 10.20882/adicciones.51

Muñoz, J., and Navas, E. (2004). Conducta antisocial en adolescentes: teorías explicativas psicosociales [Antisocial behavior in adolescents: psychosocial explanatory theories]. Psiquis 25, 79-86.

Nakamoto, J., and Schwartz, D. (2010). Is peer victimization associated with academic achievement? A meta-analytic review. Soc. Dev. 19, 221-242. doi: 10.1111/j.1467-9507.2009.00539.x

Paciello, M., Fida, R., Tramontano, C., Cole, E., and Cerniglia, L. (2013). Moral dilemma in adolescence: the role of values, prosocial moral reasoning and moral disengagement in helping decision making. Eur. J. Dev. Psychol. 10, 190-205. doi: 10.1080/17405629.2012.759099

Pahlavan, F., and Andreu, J. M. (2009). Sex-specific effects of sociocultural changing on aggression: fact or artefact? J. Organ. Trans. Soc. Change 2, 106-131. doi: $10.1386 /$ jots.6.2.103_1

Patrick, C. J., Fowles, D. C., and Krueger, R. F. (2009). Triarchic conceptualization of psychopathy: developmental origins of disinhibition, boldness and meanness. Dev. Psychopathol. 21, 913-938. doi: 10.1017/S0954579409000492

Peach, H. D., and Gaultney, J. F. (2013). Sleep, impulse control, and sensationseeking predict delinquent behavior in adolescents, emerging adults, and adults. J. Adolesc. Health 53, 293-299. doi: 10.1016/j.jadohealth.2013.03.012

Peña, M. E., and Graña, J. L. (2006). Agresión y conducta antisocial en la adolescencia: una integración conceptual [Aggression and antisocial behavior in adolescence: a conceptual integration]. Psicopatol. Clín. Leg. Forense. 1, 9-23.

Pérez-Fuentes, M. C., Gázquez, J. J., Mercader, I., Molero, M. M., and García, M. M. (2011). Rendimiento académico y conductas antisociales y delictivas en alumnos de educación secundaria obligatoria [Academic achievement and antisocial behavior in public secondary education students]. Intern. J. Psychol. Psychol. Ther. 11, 401-412.

Pérez-Fuentes, M. C., Gázquez, J. J., Molero, M. M., Cardila, F., Martos, A., Barragán, A. B., et al. (2015). Impulsividad y consumo de alcohol y tabaco en adolescentes [Adolescent impulsiveness and use of alcohol and tobacco]. Eur. J. Invest. 5, 371-382. doi: 10.1989/ejihpe.v5i3.139 
Preddy, T. M., and Fite, P. J. (2012). Differential associations between relational and overt aggression and children's psychosocial adjustment. J. Psychopathol. Behav. Assess. 34, 182-190. doi: 10.1007/s10862-011-9 274-1

Seisdedos, N. (1995). Cuestionario, A.-D., Conductas Antisociales-Delictivas [Antisocial-Delinquent Behaviors-Questionnaire]. Madrid: TEA.

Siu, A. F. Y. (2009). Trait emotional intelligence and its relationships with problem behavior in Hong Kong adolescents. Pers. Individ. Dif. 47, 553-557. doi: 10.1016/j.paid.2009.05.004

Sousa, C., Herrenkohl, T. I., Moylan, C. A., Tajima, E. A., Klika, J. B., Herrenkohl, R. C., et al. (2011). Longitudinal study on the effects of child abuse and children's exposure to domestic violence, parent-child attachments, and antisocial behavior in adolescence. J. Interpers. Violence 26, 111-136. doi: $10.1177 / 0886260510362883$

Thomas, C. R. (2010). “Oppositional defiant and conduct disorder," in Dulcan's Textbook of Child and Adolescent Psychiatry, ed M. K. Dulcan (Arlington, AL: American Psychiatric Publishing), 223-239.

Tolan, P. H., Dodge, K., and Rutter, M. (2013). "Tracking the multiple pathways of parent and family influence on disruptive behavior disorders," in Disruptive Behavior Disorders, eds P. H. Tolan and B. Leventhal (New York, NY: Springer), 161-191.

Valle, A., Regueiro, B., Rodríguez, S., Piñeiro, I., Freire, C., Ferradás, M., et al. (2015). Perfiles motivacionales como combinación de expectativas de autoeficacia y metas académicas en estudiantes universitarios [Motivational profiles as a combination of self-efficacy expectations and academic goals in university students]. Eur. J. Educ. Psychol. 8, 1-8.
Van der Graaff, J., Branje, S., De Wied, M., and Meeus, W. (2012). The moderating role of empathy in the association between parental support and adolescent aggressive and delinquent behavior. Aggress. Behav. 38, 368-377. doi: 10.1002/ab.21435

White, S. T., and Frick, P. J. (2010). "Callous-unemotional traits and their importance to causal models of severe antisocial behavior in youth," in Handbook of Child \& Adolescent Psychopathy, eds R. T. Salekin and D. R. Lynam (New York, NY: Guilford Press), 135-155.

Conflict of Interest Statement: The authors declare that the research was conducted in the absence of any commercial or financial relationships that could be construed as a potential conflict of interest.

The reviewer DÁ and the handling Editor declared their shared affiliation, and the handling Editor states that the process nevertheless met the standards of a fair and objective review.

Copyright (c) 2016 Molero Jurado, Pérez Fuentes, Luque De La Rosa, Martos Martínez, Barragán Martín and Simón Márquez. This is an open-access article distributed under the terms of the Creative Commons Attribution License (CC $B Y)$. The use, distribution or reproduction in other forums is permitted, provided the original author(s) or licensor are credited and that the original publication in this journal is cited, in accordance with accepted academic practice. No use, distribution or reproduction is permitted which does not comply with these terms. 